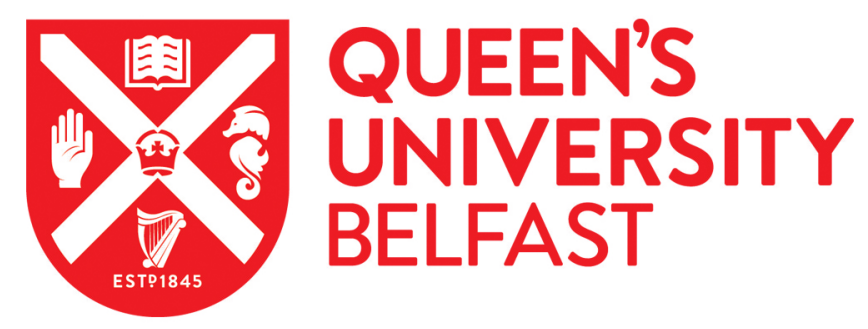

\title{
Rational design of a (S)-selective-Transaminase for asymmetric synthesis of (1S)-1-(1,1'-biphenyl 2-yl)ethanamine
}

Dourado, D. F. A. R., Pohle, S., Carvalho, A. T. P., Dheeman, D. S., Caswell, J. M., Skvortsov, T., Miskelly, I., Brown, R. T., Quinn, D. J., Allen, C. C. R., Kulakov, L., Huang, M., \& Moody, T. S. (2016). Rational design of a (S)-selective-Transaminase for asymmetric synthesis of (1S)-1-(1,1'-biphenyl 2-yl)ethanamine. ACS Catalysis, 6(11), 7749. https://doi.org/10.1021/acscatal.6b02380

\section{Published in:}

ACS Catalysis

Document Version:

Peer reviewed version

Queen's University Belfast - Research Portal:

Link to publication record in Queen's University Belfast Research Portal

Publisher rights

This document is the Accepted Manuscript version of a Published Work that appeared in final form in ACS Catalysis, copyright $\odot 2016$ American Chemical Society after peer review and technical editing by the publisher. To access the final edited and published work see: http://pubs.acs.org/doi/abs/10.1021/acscatal.6b02380

\section{General rights}

Copyright for the publications made accessible via the Queen's University Belfast Research Portal is retained by the author(s) and / or other copyright owners and it is a condition of accessing these publications that users recognise and abide by the legal requirements associated with these rights.

Take down policy

The Research Portal is Queen's institutional repository that provides access to Queen's research output. Every effort has been made to ensure that content in the Research Portal does not infringe any person's rights, or applicable UK laws. If you discover content in the Research Portal that you believe breaches copyright or violates any law, please contact openaccess@qub.ac.uk. 


\section{Rational design of a (S)-selective-transaminase for}

\section{asymmetric synthesis of (1S)-1-(1,1'-biphenyl-2-}

\section{yl)ethanamine}

Daniel F.A.R. Dourado ${ }^{1,2 \ddagger}$, Stefan Pohle ${ }^{2 \ddagger}$, Alexandra T.P. Carvalho ${ }^{1,2 \ddagger}$, Dharmendra S. Dheeman $^{2}$, Jill M. Caswell ${ }^{2}$, Timofey Skvortsov ${ }^{2,3}$, Iain Miskelly ${ }^{2}$, Rodney T. Brown ${ }^{2}$, Derek J. Quinn $^{2}$, Christopher C.R. Allen ${ }^{3}$, Leonid Kulakov ${ }^{3}$, Meilan Huang ${ }^{1,{ }^{*}}$, \& Thomas S. Moody ${ }^{2}$

1. School of Chemistry and Chemical Engineering, Queen's University Belfast, David Keir Building, Stranmillis Road, Belfast BT9 5AG, Northern Ireland, UK

2. Almac Sciences, Department of Biocatalysis and Isotope Chemistry, 20 Seagoe Industrial Estate, Craigavon BT63 5QD, Northern Ireland, UK

3. School of Biological Sciences, Queen's University Belfast, Medical Biology Centre, 97 Lisburn Road, Belfast BT9 7BL, Northern Ireland, UK 


\section{Abstract}

Amine transaminases offer an environmentally sustainable synthesis route for the production of pure chiral amines. However, their catalytic efficiency towards bulky ketone substrates is greatly limited by steric hindrance and therefore presents a great challenge for industrial synthetic applications. Hereby we report an example of rational transaminase enzyme design to help alleviate these challenges. Starting from the Vibrio fluvialis amine transaminase that has no detectable catalytic activity towards the bulky aromatic ketone 2-acetylbiphenyl, we employed a rational design strategy combining in silico and in vitro studies to engineer the transaminase enzyme with a minimal number of mutations, achieving an high catalytic activity and high enantioselectivity. We found that by introducing two mutations W57G/R415A detectable enzyme activity was achieved. The rationally designed best variant, W57F/R88H/V153S/K163F/I259M/R415A/V422A, showed an improvement in reaction rate by $>1716$-fold towards the bulky ketone under study, producing the corresponding enantiomeric pure (S)-amine (ee value of $>99 \%$ ).

KEYWORDS: biocatalysis, rational enzyme design, transaminases, molecular dynamics simulations, enzyme kinetics 


\section{Introduction}

There is a high demand in the pharmaceutical and agrochemical industry for efficient synthesis of enantiomerically pure chiral amines, which are important building blocks for the preparation of pharmaceuticals and agrochemicals. As of 2006 90\% of the FDA approved drugs were chiral compounds ${ }^{1}$. Amine transaminases (TAms) offer a green synthesis route for the production of pure chiral amines ${ }^{2}$. TAms catalyse (in many instances with great stereoselectivity) the transfer of an amino group from a primary amine compound to a ketone compound and vice-versa, using pyridoxal phosphate (PLP) as cofactor. The generally accepted catalytic mechanism of TAms consists of two half reactions in a ping-pong bi-bi mechanism (Fig. 1a) $)^{3}$. In the first half reaction, an internal aldimine that is formed between a PLP bound to the enzyme (E: PLP) and a catalytic lysine reacts with the amino donor, yielding an external aldimine. A neutral lysine residue is released which then catalyzes internal hydrogen rearrangement via a planar quinonoid intermediate, yielding a ketimine. In the second half reaction, the ketimine is hydrolyzed, releasing the product ketone and yielding a pyridoxamine 5'-phosphate (PMP) bound to the enzyme (E: PMP). Then a ketimine complex is formed between the E: PMP and the substrate ketone, which finally regenerates the E: PLP via a second planar quinonoid intermediate and external aldimine, yielding the secondary chiral amine product. 
a

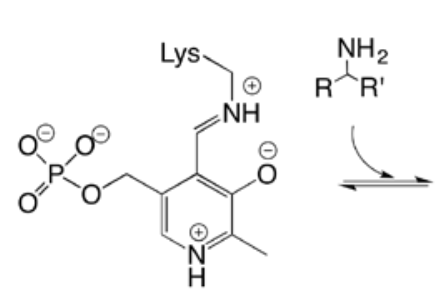

Internal aldimine (E:PLP)

amine 2

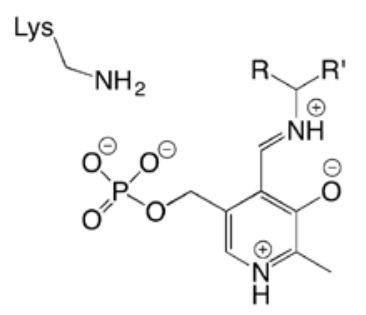

External aldimine
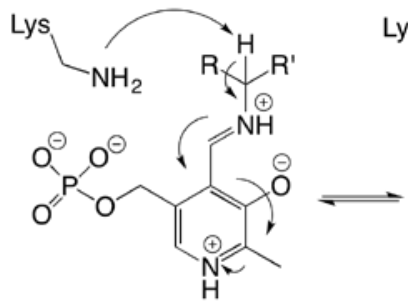

External aldimine

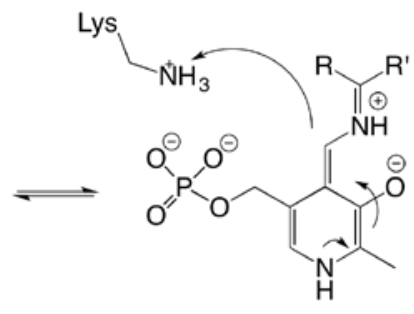

Planar quinonoid

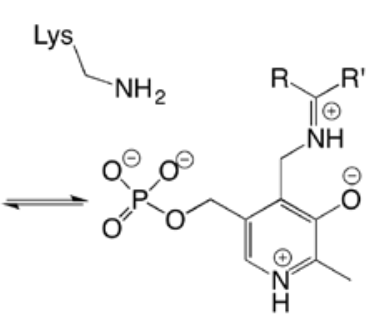

Ketimine

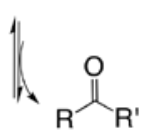

Lys

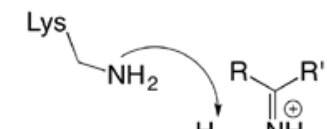

$\mathrm{H}-\mathrm{NH}$<smiles></smiles>

Planar quinonoid

E:PMP

b

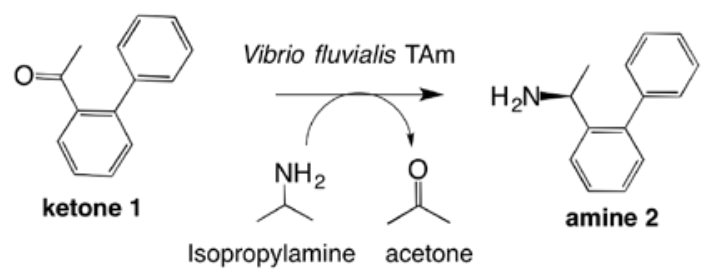

Figure 1. (a) General mechanism of the TAm-catalyzed transamination reaction where a ketone is converted to the corresponding amine. The upper panel shows the first half reaction and the lower panel shows the second half reaction. The intermediates investigated in this study were the E:PMP:substrate complex, the enzyme:planar quinonoid and the succeeding enzyme:external aldimine. (b). Asymmetric synthesis of (1S)-1-(1,1'-biphenyl-2-yl)ethanamine (amine 2). The transamination reaction under study is between the substrate 2-acetylbiphenyl (ketone 1) and the amine donor Isopropylamine and catalyzed by $V$. fluvialis TAm. 
The catalytic site of these enzymes can accommodate ketones as well as amines, and can be divided into large and small binding pockets (Fig. S1) ${ }^{4}$. The large binding pocket has a dual recognition capacity accommodating not only the bulky substituents of amines and ketones but also the carboxyl group of amino acids, pyruvate, etc. ${ }^{4 a}$. The small binding pocket adjacent to PLP accommodates small substituents and tends to repel the carbonyl group of substrates ${ }^{4 a}$.

Notwithstanding the intrinsic promiscuous nature of these enzymes their catalytic efficiency towards large ketone substrates is greatly limited by the steric hindrance ${ }^{4 b}$. Therefore, it is necessary to expand the scope of these enzymes to accommodate bulkier substrates.

Some significant advances in the engineering of TAms have been achieved recently. One of the most relevant studies was the engineering of the (R)-selective-TAm from Arthrobacter sp. to produce sitagliptin starting from prositagliptin ketone ${ }^{5}$. The initial modelling-aided site-saturated mutagenesis protocol allowed the design of a mutated enzyme that provides a modest $0.7 \%$ conversion of prositagliptin ketone. Starting from this mutant, an impressive improvement in catalysis was achieved by numerous rounds of direct evolution that culminated in an enzyme with 89\% conversion. However, 27 amino acids had to be mutated in this process.

The (S)-selective-TAms were also engineered to catalyse ketones larger than the native amine-acceptor pyruvate (Fig. S2) ${ }^{6}$. Midelfort et al. obtained a rationally engineered Vibrio fluvialis TAm_F19W/W57F/F85A/R88K/V153A/K163F/I259V/R415F and improved the catalytic conversion of (R)-ethyl 5-methyl 3-oxooctanoate by 60-fold following an in silico and saturation mutagenesis protocol ${ }^{6 a}$; Park et al. improved the amination of 2-oxo-octanoate by 4fold with a Paracoccus denitrificans mutant TAm_V153A by following an alanine-scanning mutagenesis protocol that involved mutating six active site residues in the small binding pocket (L56, V153, F19, B:F85, L56, Y150 and L417) ${ }^{6 b}$. Han et al. studied in detail the transformation 
of some non-native ketones catalyzed by TAm from Ochrobactrum anthropi following an alanine-scanning mutagenesis protocol where the small-pocket-forming residues Y20, L57, W58, V154, F86, Y151 and B:T324 were mutated ${ }^{6 c, 6 d}$. They improved the reaction rate of this TAm towards butyrophenone by 110 -fold with mutant $\mathrm{L} 57 \mathrm{~A}^{6 \mathrm{~d}}$ and improved the $\mathrm{k}_{\mathrm{cat}} / \mathrm{K}_{\mathrm{M}}$ towards acetophenone by 340-fold with mutant W58L $\mathrm{L}^{6 \mathrm{c}}$. Moreover, advances have also been made for the conversion of relevant amines into ketones and aldehydes by mutating $V$. fluvialis TAm. Nobili et al. increased the conversion of (S)-1-phenylbutylamine to the corresponding ketone by 30-fold with TAm_F85L/V153A ${ }^{6 e}$, Genz et al. got a 3-fold improvement in the conversion of the same amine to pentanal by mutating W57 and R4156f, Cho et al. got a 41 -fold improvement in the conversion of 4-phenylbutylamine by mutating W5768.

However, when compared with the aforementioned (R)-selective TAm case ${ }^{5}$, the improvement in the catalytic efficiency of (S)-selective TAms is moderate and the ketone substrates are not significantly bulkier than the native substrates. Further efforts are necessary to obtain an efficient (S)-selective-TAm that can convert bulky ketone substrates, producing pure chiral amine compounds.

In this study, we rationally engineered the (S)-selective TAm from $V$. fluvialis to catalyse 2acetylbiphenyl (ketone $\mathbf{1}$ ) to the corresponding amine (amine 2), using isopropylamine which has been suggested to be an ideal amino donor for asymmetric amination of ketones (Fig. 1b.). The wild type (WT) enzyme showed no detectable catalysis towards the bulky ketone $\mathbf{1}$ while the best variant with only seven mutations converted $42 \%$ of $1 \mathrm{~g} / \mathrm{L}$ of the substrate yielding the corresponding (S)-amine product with an enantiomeric excess (ee) value of $>99 \%$ (Table1). This corresponds to an improvement in the reaction rate by > 1716-fold (Table 1). 
The rational design in this study is based on an iterative strategy that combines state-of-theart in silico with in vitro methodologies to engineer TAm as new biocatalysts. The high conversion efficiency associated with the engineered enzyme adds an excellent example in the existing scarce successes in expanding the substrate scope of the enzymes to obtain pure chiral amine products. This strategy substantially decreases the screening effort requested by traditional directed evolution methods based on error-prone polymerase chain reaction, DNA shuffling and saturation mutagenesis, and provides a new approach in reshaping the binding pocket of the enzymes to catalyze industrially impeded reactions.

\section{Methods}

The designed $V$. fluvialis_TAm variants resulted from an iterative rational strategy that involves exhaustive structural analysis, molecular docking, MD simulations, Quantum Mechanics calculations, in silico protein structural stability study, co-evolution network analysis and in vitro screening. In total, 113 mutants were rationally designed and assessed in vitro.

\section{Computational methods}

The substrate ketone 1 (Fig. 1, S2) was docked into the WT V. fluvialis TAm (PDB code: $4 \mathrm{E} 3 \mathrm{Q})^{6 \mathrm{a}}$ and to the rationally designed mutants. The enzyme was modelled in presence of the PMP cofactor intermediate (Fig. S7a). All systems were subsequently submitted to molecular dynamics simulations (RMSD, the root mean square deviation of the alpha-carbon atoms can be seen in Fig. S11). To assess the enantioselectivity of the selected $V$. fluvialis variants we docked to them the planar quinonoid. For the best variant we additionally analysed the pro-(S) external aldimine intermediate. Both the planar quinonoid and the pro-(S) external aldimine structures of 
the best variant were submitted to molecular dynamics simulations (RMSD of the alpha-carbon atoms can be seen in Fig. S12 and Fig. S13).

\section{Parameterization of the substrate}

The geometries of the substrate ketone $\mathbf{1}$ and its corresponding planar quinonoid and pro-(S) external aldimine intermediates were initially optimized in Gaussian $09^{7}$ using Density Functional Theory (DFT) method with the exchange-correlation functional B3LYP and the 631g(d) basis set ${ }^{\underline{\theta}}$, following a procedure employed in the previous literature $\stackrel{9}{ }$. The effect of solvent was approximately considered using the Polarizable Continuum Model (PCM) ${ }^{10}$, as implemented in Gaussian 09, with the dielectric constant of water being set to 80. Atomic point charges were then calculated by fitting the HF/6-31g(d) generated electrostatic potential to atomic point charges using the RESP algorithm ${ }^{11}$. These point charges were subsequently used in the docking calculations and MD simulations.

\section{Molecular docking}

Starting with the WT crystal structure, the models of the variants were built using the mutation tool and side chain rotamer search algorithm of the Swiss pdb viewer software ${ }^{12}$. Molecular docking was performed using the AutoDock 4.2 suite with the Lamarckian genetic algorithm (LGA) and the standard free energy scoring function ${ }^{13}$. A grid box was centred on the amino group of the PMP cofactor. The catalytic lysine was deprotonated. A total of 100 LGA runs were carried out for each ligand:protein complex. The population was 300, the maximum number of generations was 27,000 and the maximum number of energy evaluations was 2,500,000. For each system analysed the top ranked structure corresponds to lowest binding energy structure of the most populated cluster with the lowest mean binding energy. 


\section{Molecular dynamics}

Molecular dynamics (MD) simulations were performed for the WT enzyme and the variants using the Amber molecular dynamics program (AMBER14) ${ }^{14}$ with the parm99SB ${ }^{15}$ and $\mathrm{GAFF}^{16}$ force fields. The structures were placed within a truncated octahedral box (spacing distance of 10 $\AA$ ) of TIP3P waters and counter ions were added to neutralize the system. The systems were first subjected to two energy minimizations using the steepest descent and conjugate gradient algorithms and were subsequently slowly heated to $300 \mathrm{~K}$ during $50 \mathrm{ps}$ with small restraints of $10 \mathrm{kcal} / \mathrm{mol} / \AA \AA$ (to all atoms except waters and ions) in a NVT ensemble using Langevin dynamics. For each system under study, three 10-ns production simulations with random initial velocities were carried out at $300 \mathrm{~K}$ in the NPT ensemble using Langevin dynamics with a collision frequency of $1.0 \mathrm{ps}^{-1}$. Constant pressure periodic boundary conditions were imposed with an average pressure of $1 \mathrm{~atm}$. Isotropic position scaling was used to maintain pressure with a relaxation time of 2 ps. The time step was set to 2 fs. SHAKE constraints were applied to all bonds involving hydrogen atoms ${ }^{17}$. The particle mesh Ewald (PME) method was used to calculate electrostatic interactions with a cut-off distance of $10 \AA^{18}$.

\section{Co-evolution network}

The co-evolution network of PLP-dependent aminotransferase superfamily - Ornithintransaminase like family ( 30,000 sequences) was calculated using Comulator software ${ }^{19,20}$. Standard parameters were used.

\section{Prediction of binding energy}

We used the Zone Equilibration of Mutants (ZEMu) protocol to predict the change in binding free energy upon amino acid substitution $(\Delta \Delta \mathrm{G})^{21}$, as implemented in $\mathrm{MMB}^{22}$. In this protocol 
first a flexibility zone is defined, which includes the residue to mutate plus two residues on each side. The flexibility zone is treated in torsion space while the rest of protein is rigid. Then a physics zone is established. This includes all residues within $12 \AA$ of the flexibility zone, inside of which PARM99 electrostatic and van der Waals forces are active. After equilibration of the flexibility zone the energy is evaluated with the $\mathrm{KB}$ potential Fold $\mathrm{X}^{23}$. The calculation is performed for both the WT $\Delta \mathrm{G}_{\mathrm{wt}}$ and the mutant $\Delta \mathrm{G}_{\mathrm{mut}}$. An estimate of the experimental change in binding free energy, $\Delta \Delta \mathrm{G}_{\mathrm{exp}}$, is obtained by $\Delta \mathrm{G}_{\mathrm{mut}}-\Delta \mathrm{G}_{\mathrm{wt}}$.

\section{Experimental methods}

\section{Chemicals}

The starting material ketone 1 (Fig. 1, S2a) was purchased from Fluorochem (Hadfield, UK) and the product standard (1S)-1-(2-Biphenylyl)ethanamine was purchased from AP Bioscience, LLC (Princeton, USA). 1-acetophenone was purchased from Sigma-Aldrich (Dorset, UK) and racemic $\alpha$-methylbenzylamine was obtained from AlfaAesar (Heysham, UK). PLP was obtained from AlfaAesar (Heysham, UK), Isopropylamine hydrochloride from Tokyo Chemical Industry UK Ltd. (Oxford, UK) and mono and dibasic potassium phosphate from Sigma-Aldrich (Dorset, UK). Components of bacterial cultures were purchased from Sigma-Aldrich (Dorset, UK), VWR Chemicals (Lutterworth, UK), kanamycin from ForMedium (Hunstanton, UK) and Isopropylthiogalactosid (IPTG) from Carbosynth (Compton, UK).

\section{Gene synthesis and cloning}

The genes for the $V$. fluvialis TAm WT and mutant variants designed in this work were commercially synthesized by GenScript (Piscataway, USA). All TAm genes were cloned into the 
pET28a(+) vector using EcoRI and XhoI restriction sites and transformed into E. coli BL21(DE3) cells (Thermo Fisher Scientific).

\section{Transaminase screening}

Transformed E. coli BL21(DE3) clones carrying TAm variant plasmids were transferred into the wells of 96-deep well plates containing $500 \mu \mathrm{L}$ of $\mathrm{LB}$ medium $(10 \mathrm{~g} / \mathrm{L} \mathrm{NaCl}, 10 \mathrm{~g} / \mathrm{L}$ tryptone, $5 \mathrm{~g} / \mathrm{L}$ yeast extract) supplemented with $50 \mu \mathrm{g} / \mathrm{mL}$ kanamycin. Plates were sealed with breathable heat seals and incubated at $37^{\circ} \mathrm{C}$ and $1400 \mathrm{rpm}$ in a plate incubator (MB100-4A, Hangzhou Allsheng Instruments Co.,Ltd, China) overnight. For protein expression, $10 \mu \mathrm{L}$ preculture was transferred into $490 \mu \mathrm{L}$ fresh LB medium supplemented with $50 \mu \mathrm{g} / \mathrm{mL}$ kanamycin in new 96-deep well plates. The plates were sealed with breathable heat seals and incubated for 2-3 hours followed by addition of IPTG to a final concentration of $1 \mathrm{mM}$. Plates were resealed with breathable seals and further incubated at $25^{\circ} \mathrm{C}$ and $1400 \mathrm{rpm}$. Subsequently the cells were pelleted by centrifugation at $4500 \mathrm{rpm}$ (Rotina 420, Hettich), the supernatant discarded and the plate with the cell pellets frozen at $-20^{\circ} \mathrm{C}$.

For TAm activity screenings, plates were thawed and $180 \mu \mathrm{L}$ phosphate buffer $(\mathrm{pH} 8)$ containing $0.56 \mathrm{mM}$ PLP and $0.56 \mathrm{M}$ Isopropylamine hydrochloride were added to the cell pellet of each well. Following addition of $20 \mu \mathrm{L} 51 \mathrm{mM}$ ketone 1 plates were sealed with aluminium foil heat seals and incubated at $40{ }^{\circ} \mathrm{C}$ and $1500 \mathrm{rpm}$ in a plate incubator for 18 hours. Reactions were stopped by addition of $800 \mu \mathrm{L} 62.5 \%$ acetonitrile, followed by resealing of the reaction plates and mixing at $1500 \mathrm{rpm}$ in the plate incubator. Subsequently, reactions were centrifuged for $15 \mathrm{~min}$ at $4500 \mathrm{rpm}$ (Rotina 420, Hettich) and supernatants analysed by HPLC. 


\section{Preparation of TAm cell-free extract}

$1 \mathrm{~L}$ of LB medium (10 g/L NaCl, $10 \mathrm{~g} / \mathrm{L}$ tryptone, $5 \mathrm{~g} / \mathrm{L}$ yeast extract) supplemented with 50 $\mu \mathrm{g} / \mathrm{mL}$ kanamycin was inoculated with $10 \mathrm{~mL}$ of an overnight culture and incubated at $37^{\circ} \mathrm{C}$ and 180 rpm (Forma orbital shaker model 491, Thermo Scientific) until an optical density (OD) of 0.6 was reached. Subsequently, protein expression was induced by addition of IPTG to a final concentration of $1 \mathrm{mM}$ followed by an overnight incubation at $25{ }^{\circ} \mathrm{C}$. After incubation, cells were harvested by centrifugation at $4{ }^{\circ} \mathrm{C}$ and $6000 \mathrm{rpm}$ (Sorvall RC 6 plus, Thermo Scientific), resuspended in $0.1 \mathrm{M}$ potassium phosphate containing $0.25 \mathrm{mM}$ PLP and sonicated for 8 cycles of 10 seconds and cooled on ice. Following centrifugation at $6000 \mathrm{rpm}$ (Sorvall RC 6 plus, Thermo Scientific) at $4{ }^{\circ} \mathrm{C}$ supernatants were freeze-dried and the obtained cell free extract powder stored at $4{ }^{\circ} \mathrm{C}$.

\section{Purification of WT TAm and its variants}

For protein purification wild-type TAm and the four variants describe in Table 1 were expressed in E. coli BL21 (DE3). Cells bearing plasmid pET28a-TAm were cultured at $37{ }^{\circ} \mathrm{C}$ in $1 \mathrm{~L}$ of LB medium containing $50 \mu \mathrm{g} / \mathrm{mL}$ kanamycin to mid-log phase (A600nm 0.6). Before protein induction, with $1 \mathrm{mM}$ IPTG, LB medium was allowed to cool down to $25^{\circ} \mathrm{C}$ and after induction further incubated at $25^{\circ} \mathrm{C}, 200 \mathrm{rpm}$ for 18 hours. The induced culture was centrifuged at $5000 \mathrm{rpm}$ at $4{ }^{\circ} \mathrm{C}$ for $10 \mathrm{~min}$, suspended in $20 \mathrm{~mL}$ of buffer A consisting of $50 \mathrm{mM}$ sodium phosphate buffer, $\mathrm{pH}$ 7.4, containing $0.3 \mathrm{M} \mathrm{NaCl}$ and $20 \mathrm{mM}$ imidazole to which protease inhibitor cocktail (cOmplete Mini, EDTA-free, Roche Diagnostics GmbH, Germany) was added to a final $1 \mathrm{x}$ concentration. The cells were lysed on ice using sonication (Soniprep 150, MSE Ltd., UK) at 16 $\mu \mathrm{m}$ amplitude for 9 cycles (10 seconds pulse and 10 seconds pause) for 3 min and centrifuged at $12000 \mathrm{rpm}$ for $30 \mathrm{~min}$. The supernatant was filtered through a $0.22 \mu \mathrm{m}$ syringe filter unit (Millex- 
GP, Merck Millipore Ltd., Ireland) and loaded onto a $2 \mathrm{~mL}$ HisPur Cobalt Resin (Thermo Scientific, IL USA) column, pre-equilibrated with 5 column volumes of buffer A. The column was washed (1.7 mL/min) with 50 column volumes of buffer A before TAm was eluted $(0.7 \mathrm{~mL} / \mathrm{min})$ with 2 column volumes of buffer A containing $0.25 \mathrm{M}$ imidazole and protease inhibitor cocktail. Imidazole was removed, and the protein was concentrated to $0.5 \mathrm{~mL}$ by centrifugation, washing three times with $1 \mathrm{~mL}$ of buffer A containing no imidazole, with a centrifugal filter with 3000 MWCO membrane (Amicon Ultracel 3K, Millipore Ltd., Ireland). Glycerol was added to $10 \%$ $(\mathrm{v} / \mathrm{v})$, and the purified protein was distributed in $50 \mu \mathrm{L}$ aliquots, flash-frozen in liquid nitrogen and

stored at $\quad-80{ }^{\circ} \mathrm{C}$ until use. Protein concentrations were determined by micro BCA protein assay kit (Thermo Scientific, IL USA) using BSA as a standard.

\section{Transaminase assay}

Unless otherwise specified, TAm enzyme reactions were prepared in 96-deep well plates by mixing $100 \mu \mathrm{L} 20 \mathrm{mg} / \mathrm{mL}$ cell free TAm extract in phosphate buffer (pH 8) with $80 \mu \mathrm{L}$ phosphate buffer (pH 8) containing 2.5 mM PLP and 2.5 M Isopropylamine hydrochloride, followed by addition of $20 \mu \mathrm{L} 51 \mathrm{mM}$ ketone $\mathbf{1}$. Plates were sealed with aluminium foil heat seals and incubated at $40{ }^{\circ} \mathrm{C}$ and $1500 \mathrm{rpm}$ in a plate incubator (MB100-4A, Hangzhou Allsheng Instruments Co., Ltd, China) for 18 hours.

Reactions were stopped by addition of $800 \mu \mathrm{L} 62.5 \%$ acetonitrile, followed by resealing of the reaction plates and mixing at $1500 \mathrm{rpm}$ in the plate incubator. Subsequently, reactions were centrifuged for 15 min at 4500 rpm (Rotina 420, Hettich) and supernatants analysed by HPLC. 


\section{Determination of kinetic parameters}

Apparent kinetic parameters of the purified enzymes were obtained under pseudo-onesubstrate conditions. Initial rate measurements were performed with varying concentrations of substrates (0.2-200 mM for acetophenone, $0.025-25 \mathrm{mM}$ for ketone 1), while keeping concentration of amine donor (IPA) constant at 1M. HPLC analysis was used to monitor the progress of the reactions. The kinetic parameters $\left(K_{M}\right.$ and $\left.k_{c a t}\right)$ were estimated by non-linear regression of the initial reaction rates using GraphPad Prism 6 (GraphPad Software, Inc., USA).

\section{HPLC Analysis}

\section{$\underline{\text { Ketone } 1}$}

Sample analysis was performed using an Agilent 1290 U-HPLC system equipped with a Kinetix C18 column (2.1x50mm, 100A, 1.7 $\mu$ m, Phenomenex, Macclesfield, UK) heated to $40{ }^{\circ} \mathrm{C}$ using $0.1 \%$ phosphoric acid as mobile phase A and MeCN (190 far UV grade, Romil, Waterbeach, UK) supplemented with $0.1 \%$ phosphoric acid as mobile phase B. Sample volumes of 1-10 $\mu \mathrm{L}$ were injected and analysed in the following gradient run: $10 \%$ mobile phase $\mathrm{B}$ to $95 \%$ mobile phase B in 1.0 min followed by $0.5 \mathrm{~min}$ at $95 \%$ mobile phase B and $0.5 \mathrm{~min}$ at $10 \%$ mobile phase $B$ at a flow rate of $0.5 \mathrm{~mL} / \mathrm{min}$. Conversion of ketone 1 was observed at $210 \mathrm{~nm}$.

For chiral analysis, the Agilent 1290 U-HPLC system was used with an Amylose 2 column (4.6x150mm, 1.7 $\mu \mathrm{m}$, Phenomenex, Macclesfield, UK) heated to $45^{\circ} \mathrm{C}$. Sample volumes of 10 $\mu \mathrm{L}$ were injected and analysed in a 15 min isocratic run of $65 \% 0.1 \%$ ammonium hydroxide / $35 \% \mathrm{MeCN}$ at a flow rate of $1 \mathrm{~mL} / \mathrm{min}$. Formation of amine product enantiomers was observed at $210 \mathrm{~nm}$.

Acetophenone 
Sample analysis was performed using an Agilent 1290 U-HPLC system equipped with a Kinetex C18 column ( $3 \times 100$ mm, $100 \AA$ A $2.6 \mu$ m, Phenomenex, Macclesfield, UK) heated to 40 ${ }^{\circ} \mathrm{C}$ using $0.1 \%$ phosphoric acid as mobile phase A and MeCN (190 far UV grade, Romil, Waterbeach, UK) supplemented with $0.1 \%$ phosphoric acid as mobile phase B. Sample volumes of 1-10 $\mu \mathrm{L}$ were injected and analysed in the following gradient run: $5 \%$ mobile phase B to $95 \%$ mobile phase B in 3.0 min followed by 1 min at $95 \%$ mobile phase B and $1.2 \mathrm{~min}$ at $5 \%$ mobile phase $\mathrm{B}$ at a flow rate of $0.5 \mathrm{~mL} / \mathrm{min}$. Conversion of acetophenone was observed at $210 \mathrm{~nm}$.

\section{Racemic 1-(2-Biphenylyl)ethanamine standard synthesis}

A mixture of $60 \mathrm{mg}$ ketone 1, $116 \mathrm{mg}$ ammonium formate and $60 \mathrm{mg}$ zinc in $0.7 \mathrm{ml}$ ethanol was heated to reflux under argon overnight. A further 3 equivalents of zinc and 6 equivalents of ammonium formate were added and heated under reflux continued overnight. The reaction mixture was filtered through celite and washed with ethanol. The filtrate was concentrated on rotary evaporator at $40^{\circ} \mathrm{C}$ to leave a whitish oil followed by addition of $10 \mathrm{~mL} 1 \mathrm{M} \mathrm{HCl}$ and washing with diethyl ether $(2 \mathrm{x} 20 \mathrm{~mL})$. The aqueous layer was basified to $\mathrm{pH} 10$ with ammonium hydroxide and extracted with DCM (1x 10, 2x $5 \mathrm{~mL})$. The organic layer was washed with $10 \mathrm{~mL}$ brine and dried over $\mathrm{Na}_{2} \mathrm{SO}_{4}$. Finally it was concentrated on rotary evaporator and 12 mg clear oil obtained.

\section{Thermal stability}

The thermal stability of the WT and the variants described in table 1 was measured. The reactions were carried out with $5 \mathrm{mM}$ ketone 1, 1M IPA, $0.01 \mathrm{mM}$ enzyme, $0.1 \mathrm{M} \mathrm{K}$-phosphate buffer (pH 
8.0), $10 \%$ DMSO (v/v). Enzymes in phosphate buffer were pre-incubated in 96 -well plates at $40^{\circ} \mathrm{C}$, $50^{\circ} \mathrm{C}$ and $60^{\circ} \mathrm{C}$ for $18 \mathrm{~h}$. Reactions with the pre-incubated enzyme were set up next day in parallel with control reactions. Reactions were carried out at the same temperature that was used for preincubation. After $4 \mathrm{~h}$ reactions were quenched with $62.5 \%$ acetonitrile and analysed with HPLC. All reactions were performed in triplicates.

\section{Results and Discussion}

There has been so far limited success in the engineering of (S)-selective TAm enzymes to catalyse significantly large ketone substrates ${ }^{6 a-d}$, when compared with the improvements obtained for a (R)-selective TAm enzyme ${ }^{5}$. Here we studied the conversion of ketone $\mathbf{1}$ by the homodimeric $V$. fluvialis TAm (Fig. 1b, S2). It is worth noting that ketone $\mathbf{1}$ is larger than the substrates studied in the previous research (Fig. S2) ${ }^{\text {6a-d. }}$. A substrate (R)-ethyl 5-methyl 3oxooctanoate (Fig. S2b) has a similar molecular weight, however, it is less bulky than ketone $\mathbf{1}$. In addition, until completion of this present work, WT V. fluvialis TAm has shown no detectable catalysis towards ketone $\mathbf{1}$ (Table 1), while all other studies started with measurable activities with the respective WT Tams. The design of the initial $V$. fluvialis TAm variants resulted from an exhaustive structural analysis, molecular docking and molecular dynamics simulations. After initial simulations for the WT $V$. fluvialis TAm, we observed that the substrate ketone $\mathbf{1}$ is essentially held in place by a $\pi$-stacking interaction with the side chain of F19 and a strong hydrogen bond with the indole side chain of the residue W57 (Fig. 2). However, this seems to be a non-catalytic pose because the distance between the amino group of PMP and the ketone $\mathbf{1}$ carbonyl is large (5.1 $\AA$ ) and the phenyl group of ketone $\mathbf{1}$ is turned to PMP. Thus the PMP 
nucleophilic attack to the ketone 1 carbonyl carbon seems highly improbable since the approximation of the substrate to PMP would involve a considerable steric clash (Fig. 2).

Table 1. Transamination of ketone 1 by the V. fluvialis TAm and engineered variants.

\begin{tabular}{|c|c|c|c|c|c|}
\hline & WT & W57G/R415A & $\begin{array}{l}\text { W57G/K163F/ } \\
\text { R415A }\end{array}$ & $\begin{array}{l}\text { W57G/I259M/ } \\
\text { R415A }\end{array}$ & $\begin{array}{l}\text { W57F/R88H/ } \\
\text { V153S/K163F/ } \\
\text { I259M/R415A } \\
\text { /V422A }\end{array}$ \\
\hline ee $(\%)(S)$-amine & ND & $>99$ & $>99$ & $>99$ & $>99$ \\
\hline $\begin{array}{l}\text { Conversion } \\
\left(\text { Mean } \pm \text { SD, \%) }{ }^{a}\right.\end{array}$ & ND & $2.49 \pm 0.11$ & $5.63 \pm 0.64$ & $1.9 \pm 0.13$ & $42.14 \pm 0.89$ \\
\hline$K_{M}[\mathbf{m M}]^{\mathbf{b}}$ & NA & 0.263 & 0.405 & 0.188 & 0.155 \\
\hline$k_{\text {cat }}\left[\mathrm{s}^{-1}\right]^{\mathbf{b}}$ & NA & $7.88 \times 10^{-4}$ & $3.29 \times 10^{-3}$ & $1.19 \times 10^{-3}$ & $6.68 \times 10^{-3}$ \\
\hline$k_{\text {cat }} / K_{M}\left[M^{-1} \cdot \mathrm{s}^{-1}\right]$ & NA & 3.00 & 8.13 & 6.30 & 43.0 \\
\hline $\begin{array}{l}\text { Fold increase in } \\
k_{\text {cat }} / K_{M}{ }^{c}\end{array}$ & NA & 1 & 3 & 2 & 14 \\
\hline $\begin{array}{l}\text { Reaction rate } \\
{[\mu \mathrm{M} / \mathrm{h}]^{\mathrm{d}}}\end{array}$ & $\begin{array}{l}\text { ND } \\
\mathbf{e}\end{array}$ & 14.3 & 36.2 & 14.4 & 171.6 \\
\hline $\begin{array}{l}\text { Reaction rate } \\
\text { fold increase }\end{array}$ & - & $>143$ & $>362$ & $>144$ & $>1716$ \\
\hline
\end{tabular}

a Reaction conditions: $5 \mathrm{mM}$ substrate, 1M IPA, $0.01 \mathrm{mM}$ of purified enzyme (Fig. S14), $0.1 \mathrm{M}$ potassium phosphate buffer (pH 8.0), $10 \%$ DMSO (v/v), $40^{\circ} \mathrm{C}, 18 \mathrm{~h}$. All reactions were performed in triplicates.

b Kinetic parameters are the apparent rate constants calculated from the initial reaction rates at a fixed concentration of amine donor (1M).

c Fold change with W57G/R415A as reference

d Reaction rates are initial reaction rates. Reaction conditions: $5 \mathrm{mM}$ substrate, $1 \mathrm{M}$ IPA, $0.01 \mathrm{mM}$ of purified enzyme, $0.1 \mathrm{M}$ $\mathrm{K} \cdot$ phosphate buffer (pH 8.0), $10 \%$ DMSO (v/v), $40^{\circ} \mathrm{C}$. Reactions were performed in duplicates.

e ND - not detectable. Reaction rate for WT was no more than $0.1 \mu \mathrm{M} / \mathrm{h}$, considering the detection limit.

As can be seen from the MD simulation of the WT TAm (Fig. 2), the bulky W57 is placed in the middle of the active centre and it does not provide a space large enough to accommodate the bulky substrate in a catalytic pose. Therefore, it is imperative to mutate W57 to smaller non- 
polar residue. In all our mutants this residue was mutated to alanine, glycine or phenylalanine, respectively (Table S1). Previous studies on $\omega$-TAms indicated that the enzymes’ specificity highly depends on the binding step rather than the subsequent catalytic step ${ }^{24}$. Thus, mutations introduced in the large binding pocket would not only open the pocket but also create strong intermolecular interactions with the substrate. Therefore, in addition to W57, we also focused our attention on other relevant binding pocket residues (K163, A228, E257, V258, I259, V422, R415) (Fig. S1, Table S1). On the other hand, the small binding pocket residues are positioned in the vicinity of the subunits interface. Thus, it could negatively alter the intrinsic stability of the enzyme if this pocket is excavated to fit a bulky substrate. Therefore we mutated only five residues of this pocket, namely G55, L56, H83, B: R88, V153 (Fig. S1, table S1), in order to enhance the intermolecular interactions in the subunit interface and therefore the enzyme overall structural stability. Due to the non-polar nature of the ketone substrate it is imperative to decrease the overall charge of active centre. Positions R88, K163 and R415 in V. fluvialis TAm were mutated in the synthesis of imagabalin ${ }^{6 a}$. However, in the best variant reported, the residue at the position 88 was still mutated to a positively charged lysine residue. In the present study, we decreased the overall active site charge by mutating the positively charged residues R88, K163 and R415. Additionally, we also mutated residues that interact with PMP, L56 and B: R88 (Table S1).

In total 72 mutants were assessed experimentally in the first round of in vitro screening, from which several initially designed mutants were validated to have a detectable conversion of the substrate. Those involved positions 57, 88, 153, 163, 259, 415, 422 (Table S1), among which the most efficient double mutant is V. fluvialis TAm W57G/R415A (Table 1). Subsequently, we designed multiple variants based on the screening results, structural analysis and the calculated 
evolution correlation network. The first round screening results and structural analysis indicated that better activity could be achieved by combining V. fluvialis_TAm W57G/R415A with mutations at positions $88,163,259$. The evolution correlation network of the active centre residues based on analysis of 30,000 homologous sequences disclosed obvious correlation between I259 and residues V153 and V422 (Fig. S3). This was also taken into account in the design of the new multiple mutants.

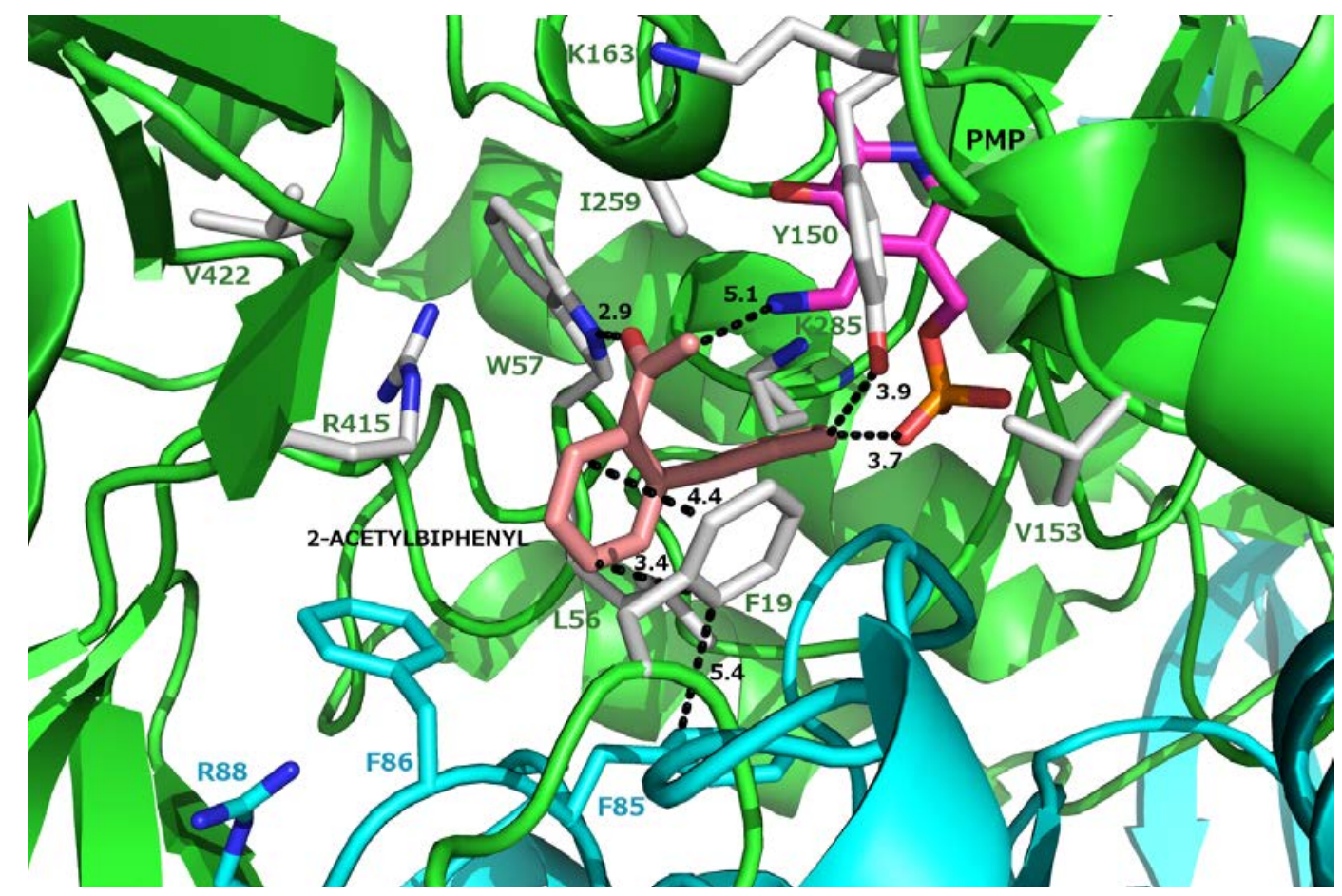

Figure 2. MD reference structure of ketone 1 docked to WT $V$. fluvialis TAm in presence of PMP. The active centre residues are represented by sticks with the carbons of Chain A (green ribbon) coloured in grey and the carbons Chain B (cyan ribbon) coloured in cyan. Relevant distances are shown $(\AA)$. The MD reference structure corresponds to the structure with lowest RMSD (alpha-carbon atoms) in relation to the average structure of the simulation. No significant changes were observed in the MD replicas. 
The designed multiple mutants were examined in silico using molecular docking and molecular dynamics simulations (the latter were based on the best docking results) and then assessed experimentally in a second round of in vitro screening (41 multiple mutants) (Table S1).

\section{Best mutants identified from rational design}

The best $V$. fluvialis TAm mutant identified from the first round in vitro screening was W57G/R415A (Fig. 3a). Introduction of the W57G substitution enlarges the active centre pocket and adds extra flexibility to the loop where this residue is located. As a result the phenyl group of ketone $\mathbf{1}$ is now far from PMP. It occupies the space vacated by the loss of the tryptophan residue and establishes London dispersion forces with the side chain of I259. The R415A substitution further opens the active centre pocket and decreases the positive charge (Fig. 3a) of the pocket, contributing to an increase in the affinity for the hydrophobic substrate. The distance between the ketone 1 carbon and the PMP amino nitrogen decreases to $3.7 \AA$, which is a much more reasonable distance for the nucleophilic attack than that observed in the WT enzyme. This distance is also comparable with the reported distance of $2.65 \AA$ for a PMP: acetophenone intermediate along the reaction path of the related Chromobacterium violaceum TAm, which was obtained from density functional theory calculations ${ }^{25}$. This double mutant provided an experimental conversion of $2.49 \%$ for ketone $\mathbf{1}$, that corresponds to an improvement in the reaction rate by $>$ 143-fold (Table 1 ). 


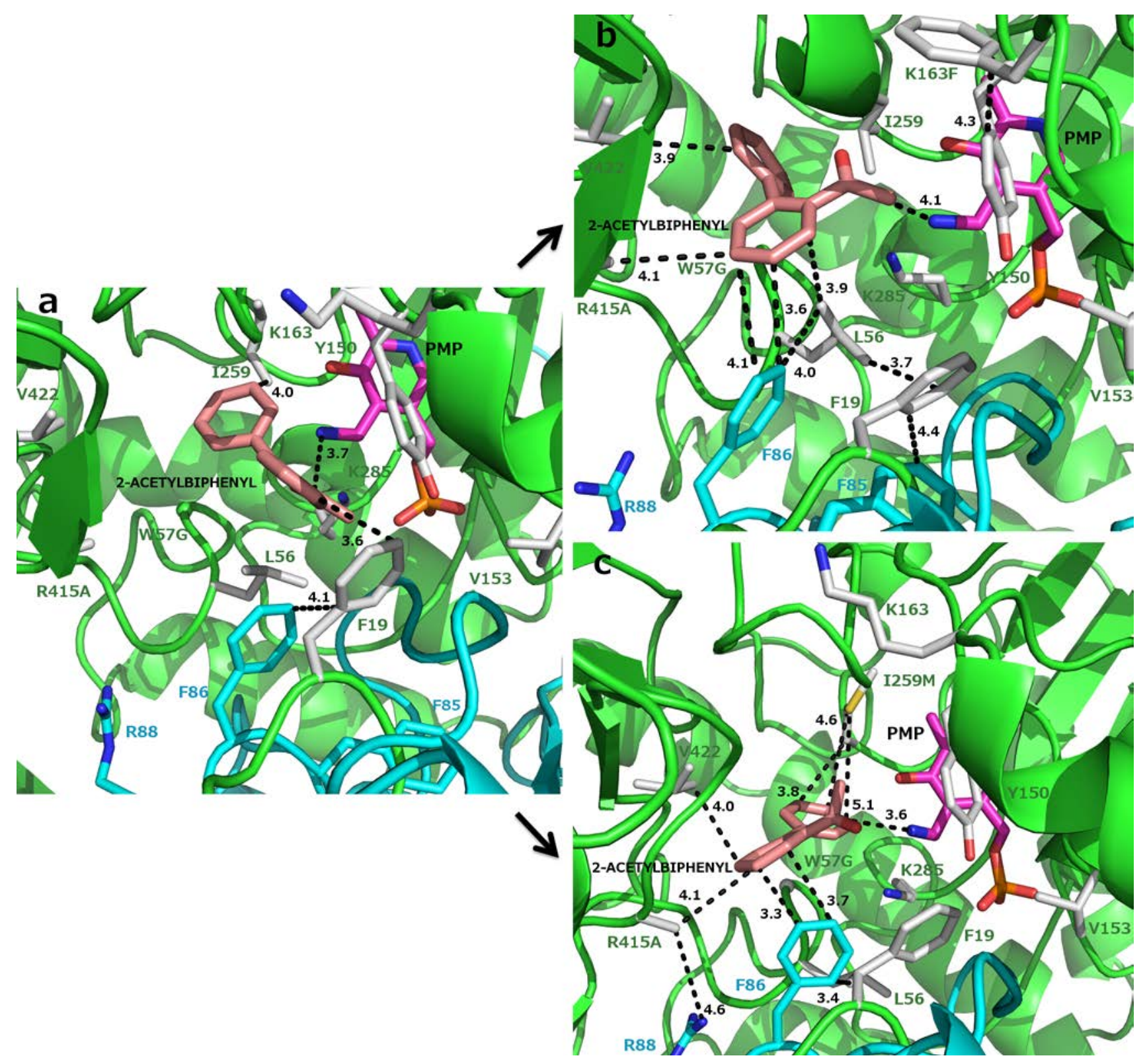

Figure 3. MD reference structures of ketone 1 docked to $V$. fluvialis TAm mutants in presence of PMP. (a) TAm_W57G/R415A (b) TAm_W57G/K163F/R415A (c)

TAm_W57G/I259M/R415A. The active centre residues are represented by sticks with the carbons of Chain A (green ribbon) coloured in grey and the carbons of Chain B (cyan ribbon) coloured in cyan. Relevant distances are shown $(\AA)$. The MD reference structure corresponds to 
the structure with lowest RMSD (alpha-carbon atoms) in relation to the average structure of the simulation. No significant changes were observed in the MD replicas.

Based on the promising catalytic activities exhibited in the first round in vitro screening, new mutants of $V$. fluvialis TAm were designed and tested in a second round in vitro screening (Table S1). Here we describe in detail two of the best triple mutants as well as the overall best multiple mutant identified from the second round screening. One of those is the variant TAm _W57G/K163F/R415A. It should be noticed that a phenylalanine at position 163 is rarely observed in the analysed homologous sequences (Fig. S4). Only $~ 0.4 \%$ of those sequences have a phenylalanine and the most common residues are the polar glutamine and asparagine residues as well as the charged lysine (Fig. S4). However, due to the non-polar nature of ketone $\mathbf{1}$ it was imperative to decrease the overall charge of active centre. To achieve this, a new variant was designed where the positively charged residues K163 and R415 were mutated into neutral residues. In this variant the hydrophobicity of the active centre is increased while the charged R415 and K163 residues were simultaneously mutated into non-polar residues alanine and phenylalanine, respectively (Fig. 3b). The substrate establishes a strong $\pi$-stacking interaction with Phe86 of chain B and is also involved in London dispersion forces with the side chains of residues L56, A415 and V422. The distance between the ketone $\mathbf{1}$ carbon and the PMP amino nitrogen is $4.1 \AA$ (Fig. 3b). In vitro analysis demonstrated that this mutant reached 5.63\% conversion of ketone $\mathbf{1}$, which is an improvement in catalytic efficiency by 3-fold over the double mutant (Table 1).

The second triple mutant $V$. fluvialis TAm W57G/R415A/I259M was designed to introduce a $\mathrm{S} / \pi$ interaction between the sulphur atom of the methionine residue 259 and the aromatic phenyl 
group of ketone 1 (Fig. 3c). S/ $\pi$ interactions between the methionine sulphur and aromatic rings are stronger than hydrophobic interactions and known to play an important role in protein stabilization $^{26}$. In addition, the methionine is less prone to oxidation while forming a stable $\mathrm{S} / \pi$ interaction. Therefore, it is beneficial to introduce such interactions in the rational design of enzymes $^{27}$. Similar to the other triple mutant (Fig. 3b), we also observed a strong $\pi$-stacking interaction between ketone $\mathbf{1}$ and the side chain of Phe86 from chain B, as well as London dispersion forces between the substrate and the side chains of residues L56, A415 and V422 (Fig. 3c). The distance between the carbonyl carbon atom of ketone $\mathbf{1}$ and the amino nitrogen atom of PMP is decreased to $3.6 \AA$. The catalytic efficiency improves by 2-fold over the double mutant (Table 1).

Based on the initial in vitro screening results, the co-evolution network and molecular modelling, we also designed multiple variants with 4 to 7 substitutions (Table S1). Among them, one variant (Fig. 4) W57F/R88H/V153S/K163F/I259M/R415A/V422A exhibit significantly improved activity. The catalytic efficiency improves by 14-fold over the double mutant (Table 1). It converts up to $42.14 \%$ of ketone $\mathbf{1}$ at $1 \mathrm{~g} / \mathrm{L}$ of substrate (Table 1 ) and corresponds to an improvement of the reaction rate by $>1716$-fold. This variant also shows an improvement in the reaction rates and kinetic parameters towards acetophenone, a standard TAM substrate (Table S2). 


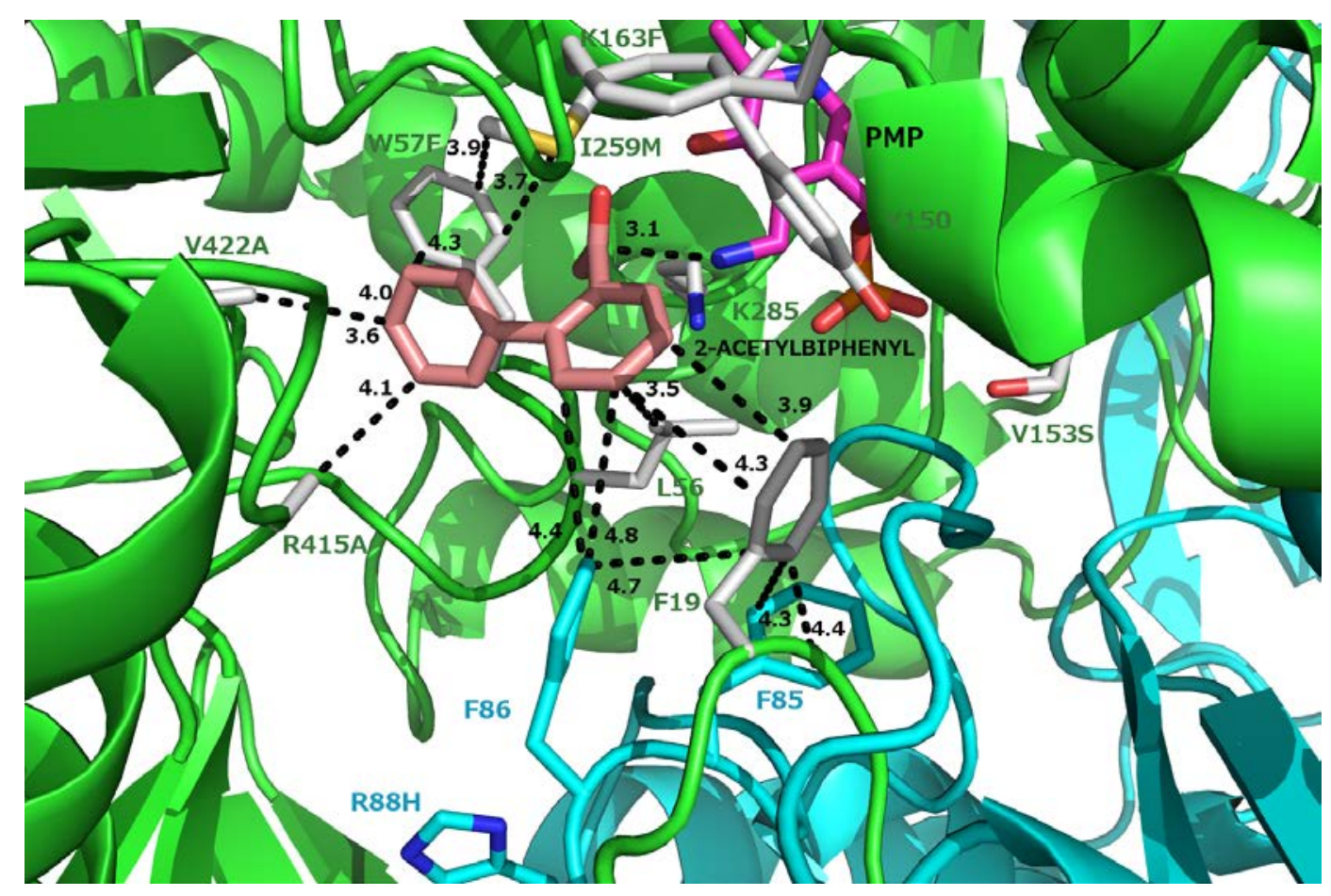

Figure 4. MD reference structure of ketone 1 docked to $V$. fluvialis TAm W57F/R88H/ V153S/K163F/I259M/V422A/R415A in presence of PMP. The active centre residues are represented by sticks with the carbons of Chain A (green ribbon) colored in grey and the carbons of Chain B (cyan ribbon) colored in cyan. Relevant distances are shown $(\AA)$. The MD reference structure corresponds to the structure with lowest RMSD (alpha-carbon atoms) in relation to the average structure of the simulation. No significant changes were observed in the MD replicas.

As previously mentioned, due to the non-polar nature of ketone $\mathbf{1}$ it was imperative to decrease the overall charge of active centre such that K163 and R415 were mutated into neutral residues. To further reduce the charge, we introduced another mutation at $\mathrm{B}: \mathrm{R} 88 \mathrm{H}$, which is located along the subunit interface and close to the active centre vicinity (Fig. 4). The position 57 was mutated into phenylalanine such that the phenyl ring of W57F simultaneously interacts with both ketone $\mathbf{1}$ and the side chain of I259M via a strong T-shaped $\pi$-stacking and a S/ $\pi$ interaction, respectively (Fig. 4). In contrast, this interaction was not observed in W57G (Fig.S5). As a result 
of these mutations, in the best variant, the substrate's acetophenone core establishes T-shaped $\pi$ stacking interactions with the side chains of both B:F86 and F19 while the latter in turn interacts with B:F85 through a T-shaped $\pi$-stacking. The side chains of V422A and R415A also interact directly with ketone $\mathbf{1}$ via hydrophobic interactions. This extremely well packed network of strong $\pi$-stacking interactions highly contributes to a stable arrangement of ketone $\mathbf{1}$ in the active centre pocket. The pose of ketone $\mathbf{1}$ is also catalytically preferable with the distance between the substrate carbonyl carbon and the PMP amino group approximately equal to $3.1 \AA$, being quite close to the distance of $2.65 \AA$ reported for the PMP: acetophenone intermediate ${ }^{25}$.

In the first round screening the position 153 nested at the subunit interface was mutated to the charged residues arginine and lysine as well as to serine and alanine (Table S1), Although the most commonly observed amino acids at this position are arginine and glutamate according to the homologous sequences studied (Fig. S4), the results of the screening and further structural analysis clearly indicated that adding a charged residue at this position was not beneficial to the activity. We therefore propose introducing of negative charge would negatively affect the overall hydrophobicity of the active centre, which is not ideal for our substrate. Thus in the second round of screening only mutant V153S was considered. Mutating the valine residue 153 into serine can introduce additional interactions with chain B via an ion-dipole interaction with K126 and a dipole-dipole interaction with H319 (Fig. S6). We calculated changes in binding free energy $(\Delta \Delta \mathrm{G})$ in the variant TAm_V153S using ZEMu ${ }^{21}$. The $\Delta \Delta \mathrm{Gv153s}$ obtained was -2.01 $\mathrm{kcal} / \mathrm{mol}$, which indicates that V153S mutation may increase the subunit interface affinity, and hence the overall structural stability of the enzyme (Fig. S6). 
Stability of the WT and engineered enzymes was examined in vitro. After 18h the best variant retains $98 \%$ and $90 \%$ of activity at $40^{\circ} \mathrm{C}$ and $50^{\circ} \mathrm{C}$, respectively, while the other variants suffer a significant decrease in activity at $50^{\circ} \mathrm{C}$ (Table S3, S4).

\section{Active centre polarity}

The active centre of the WT enzyme is positively charged (Fig.5a). Changing the polarity of the active site pocket was essential to better accommodate our non-polar substrate to increase its conversion (Fig. 5). In the mutant $V$. fluvialis TAm W57G/R415A, the charge of the active centre becomes less positive and more delocalized (Fig.5c). Substitution of the bulky hydrophobic W57 with glycine enlarges the active site pocket (Fig.5b) and the simultaneous substitution of the positively charged R415 with an alanine reduces its positive charge (Fig.5c). In the subsequent engineering of the enzyme, this double mutant is conjugated with the K163F mutation that further contributes to decrease in the positive charge of the active centre (Fig. 5e). In the best variant, $V$. fluvialis TAm W57F/R88H/V153S/K163F/I259M/R415A/V422A, the positive charges of residues R88, K163 and R415 are completely removed. Simultaneously the W57F, I259M and V422A mutations introduce a well-packed hydrophobic network, making the binding pocket more compact and the active centre substantially more neutrally charged (Fig.5f). 
a
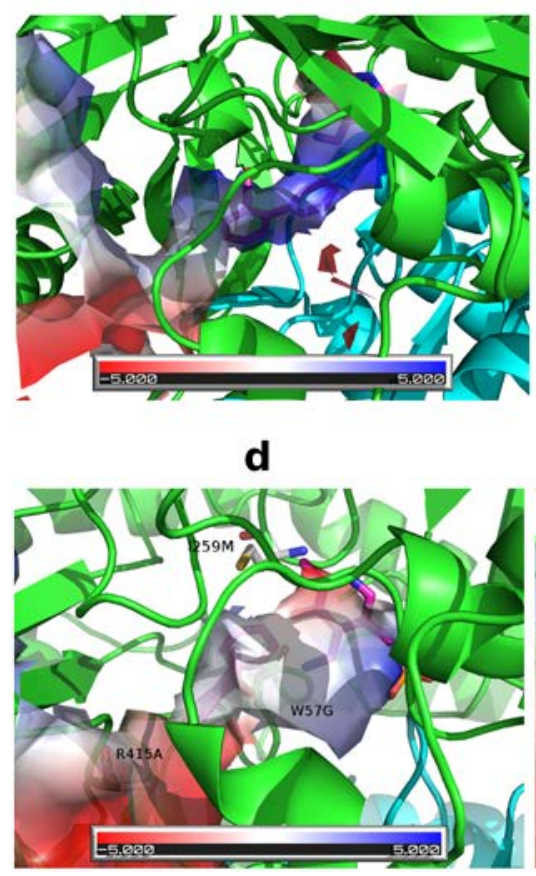

b
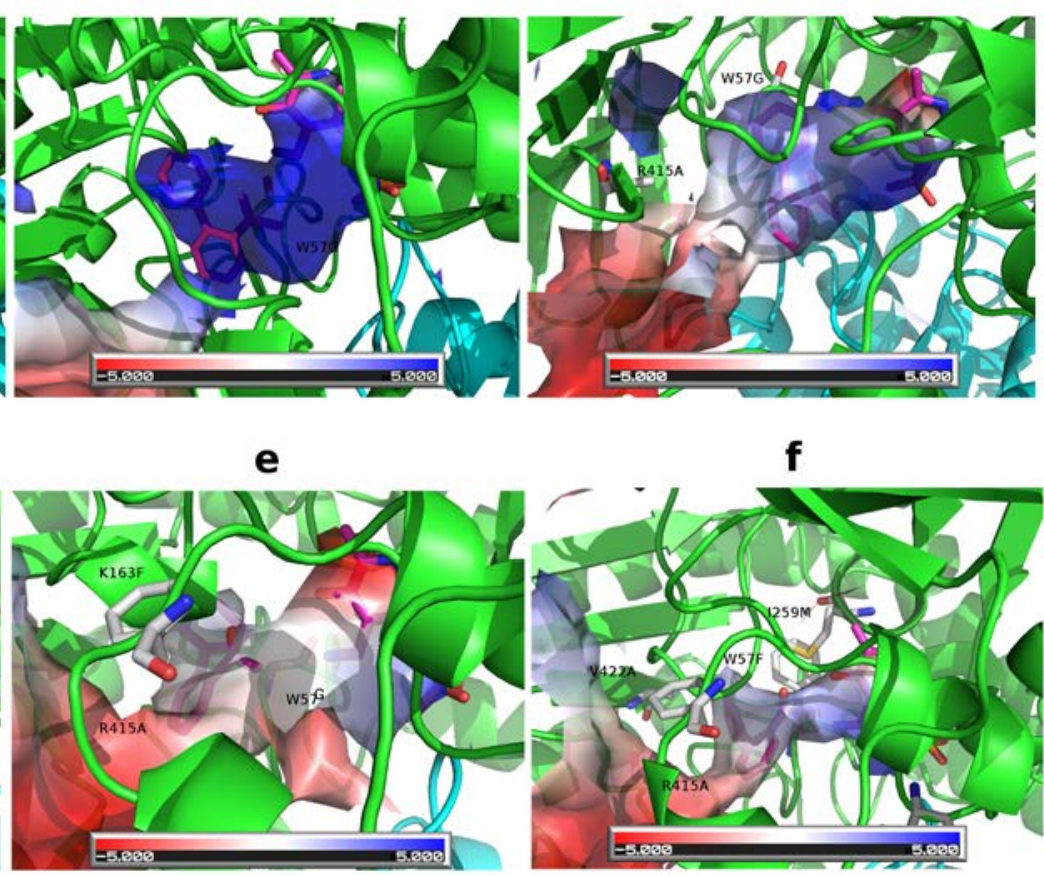

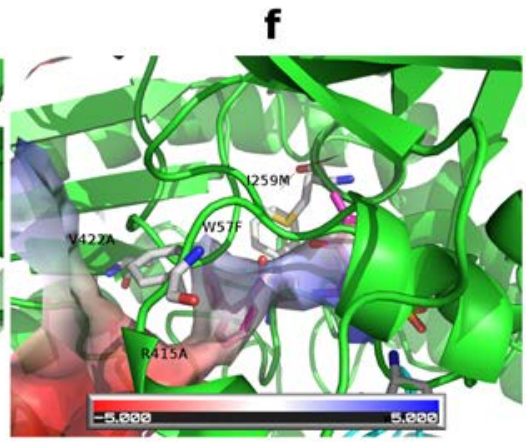

Figure 5. The electrostatic potential ( $\pm 5 \mathrm{kT} / \mathrm{e}$ ) of the MD reference structures of the $V$. fluvialis TAm (ketone 1 was docked in the presence of PMP) plotted on the solvent-accessible surface of the detected cavities. The graphs (a)-(e) indicates a progression of colors from blue (positive) to red (negative) (a) WT TAm; (b) TAm_W57G; (c) TAm_W57G/R415A; (d) TAm_W57G/ I259M/R415A; (e) TAm_W57G/K163F/R415A; (f) TAm_W57F/R88H/V153S/K163F/I259M/ R415A/V422A.

The combined effect of the favourable interactions and changes in active site polarity provides a valid explanation for the experimentally observed activity of the best variant (Table 1). 


\section{Selectivity}

In the second half-reaction of the generally accepted mechanism for $\omega$-TAm (Fig. 1), the amino acceptor and the PMP cofactor react leading to the formation of a ketimine intermediate. This is followed by proton abstraction and consequent electronic rearrangement of the ketimine intermediate, which is subsequently converted into a planar quinonoid intermediate. In the next step, the side chain of the catalytic lysine donates a proton to the nitrogen binding carbon of the planar quinonoid and an external aldimine intermediate is formed. It is at this point that the reaction specificity is determined. The half-reaction ends with the release of the product amine and the formation of a Schiff base (internal aldimine) between the aldehyde group of PLP and the side chain of the catalytic lysine. Thus, in order to assess the enantioselectivity of the mutants we focused on the study of the planar quinonoid and the pro-(S) external aldimine intermediates (Fig. S7b \& c). The spatial arrangement of the catalytic lysine with respect to the planar quinonoid commands the orientation of the amino group of the catalytic lysine, which undergoes nucleophilic attack towards the nitrogen binding carbon of the quinonoid intermediate. This consequently dictates the chirality of the resulting external aldimine. We observed that the spatial arrangement of all the variants favours the formation of pro-(S) external aldimine and consequently the formation of the end S-amine product (Fig. 6, Fig. S8, S9). For the best variant TAm_W57F/R88H/V153S/K163F/I259M/R415A/V422A we also conducted a MD analysis of the pro-(S) external aldimine. Superimposing of the MD reference structures of the planar quinonoid intermediate and the pro-(S) external aldimine demonstrates that the intermediates share an identical active centre pose, which further indicates the (S)-chiral amine is the end product synthesized by the designed variant (Fig. S10). 
In the subsequent in vitro analysis, it was confirmed that all the described mutants produce the S-amine with an enantiomeric excess (ee) of $>99 \%$ (Table1).

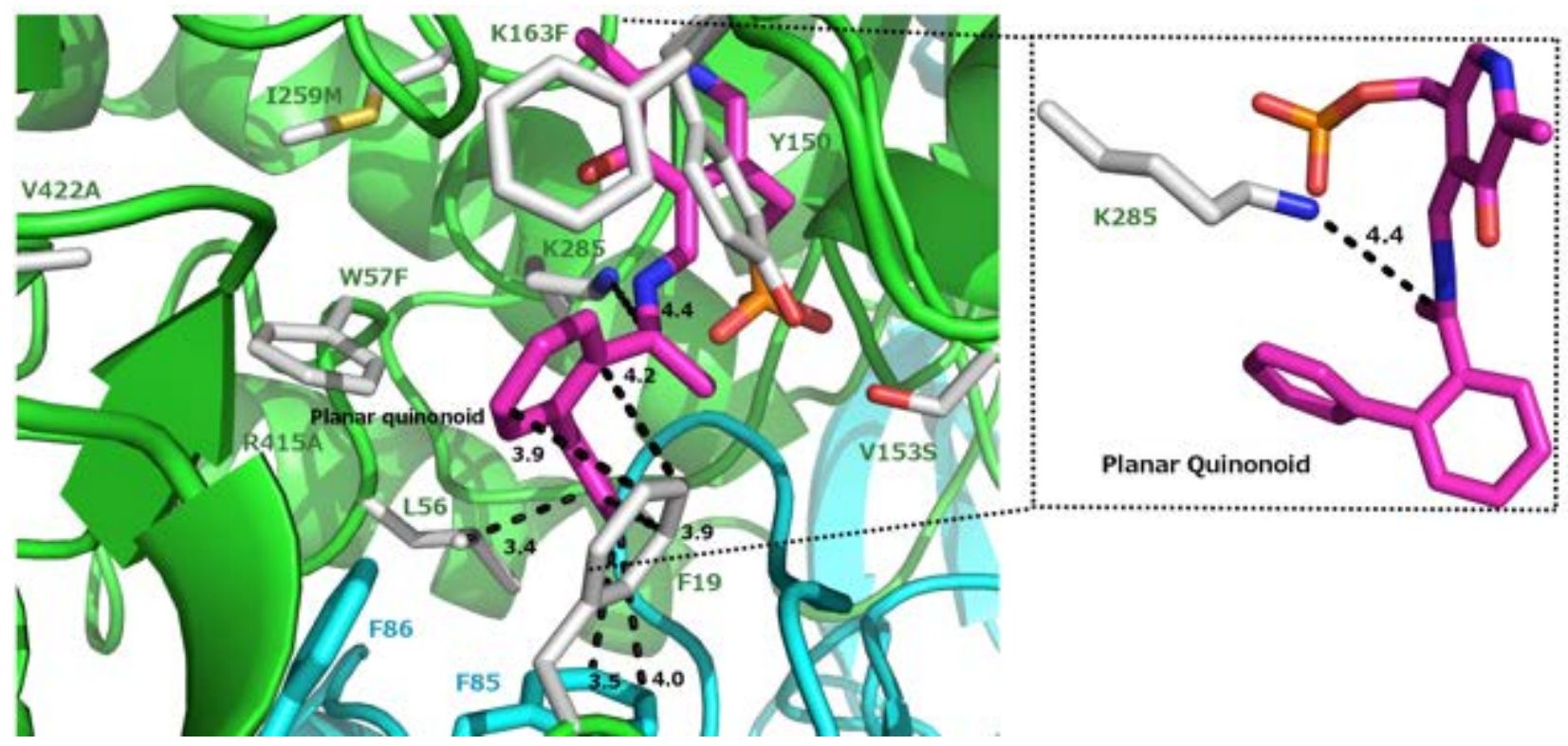

Figure 6. MD reference structure of $V$. fluvialis TAm W57F/R88H/V153S/K163F/I259M/ V422A/R415A docked into the planar quinonoid. The active centre residues are represented by sticks with the carbons of Chain A (green ribbon) colored in grey and the carbons of Chain B (cyan ribbon) colored in cyan. Relevant distances are shown ( $\AA$ ). The MD reference structure corresponds to the structure with lowest RMSD (alpha-carbon atoms) in relation to the average structure of the simulation. No significant changes were observed in the MD replicas.

\section{Conclusions}

We rational engineered the (S)-selective TAm from $V$. fluvialis to catalyze conversion of the bulky 2-acetylbiphenyl to the corresponding (S)-amine. To improve substrate binding and conversion we focused on enlarging the large binding pocket while increasing hydrophobicity at 
positions W57, M259, V422 and R415, decreasing the charge of the active centre at positions K163, R415 and B: R88 and improving the enzyme structural stability at position V153. With a minimal number of seven mutations, we designed an enzyme that shows an outstanding reaction rate improvement (> 1716-fold) and yields an enantiomeric pure (S)-amine product with ee value of $>99 \%$. This variant retains $90 \%$ of activity for $18 \mathrm{~h}$ at $50^{\circ} \mathrm{C}$.

It is noteworthy that the WT enzyme does not show any detectable activity towards 2acetylbiphenyl. Our data showed that initial weak promiscuous activities towards a substrate are not always a necessity for enzyme evolution. By correctly selecting functionally relevant mutations, multi-step rational mutagenesis can successfully provide a more efficient pathway for evolution, while Nature most commonly follows smooth weak trade-off routes, hence requiring substantial number of sequence modifications to gain a new function (i.e. new mutations accumulate while maintaining the robust native activity). Our results show that amine TAm displays a high plasticity, enabling us to evolve it with few mutations starting from an enzyme with no detectable initial promiscuous activity towards a bulky ketone substrate like 2acetylbiphenyl.

Supporting Information. The following files are available free of charge.

- Additional figures and tables. (PDF)

The authors declare no competing financial interests

\section{Corresponding Author}

*m.huang@qub.ac.uk 


\section{Author Contributions}

$\ddagger$ These authors contributed equally. (D.F.A.R. Dourado, S. Pohle, A. T.P. Carvalho)

\section{Acknowledgments}

The authors acknowledge the financial support from INVEST NI RD0314092. We are grateful for the computing resources from QUB high performance computing Centre.

\section{REFERENCES}

1. $\quad$ Nguyen, L. A.; He, H.; Pham-Huy, C. Int J Biomed Sci 2006, 2, 85-100.

2. (a) Taylor, P. P.; Pantaleone, D. P.; Senkpeil, R. F.; Fotheringham, I. G. Trends in Biotechnology 1998, 16, 412-418; (b) Koszelewski, D.; Tauber, K.; Faber, K.; Kroutil, W. Trends in Biotechnology 2010, 28, 324-332; (c) Hohn, M.; Bornscheuer, U. T. Chemcatchem 2009, 1, 42-51.

3. $\quad$ Silverman, R. B., Organic Chemistry of Enzyme-Catalyzed Reactions. 2nd edition ed.; Academic Press: 2002; p 800.

4. $\quad$ (a) Shin, J. S.; Kim, B. G. J Org Chem 2002, 67, 2848-53; (b) Steffen-Munsberg, F.; Vickers, C.; Thontowi, A.; Schatzle, S.; Meinhardt, T.; Humble, M. S.; Land, H.; Berglund, P.; Bornscheuer, U. T.; Hohne, M. Chemcatchem 2013, 5, 154-157.

5. $\quad$ Savile, C. K.; Janey, J. M.; Mundorff, E. C.; Moore, J. C.; Tam, S.; Jarvis, W. R.; Colbeck, J. C.; Krebber, A.; Fleitz, F. J.; Brands, J.; Devine, P. N.; Huisman, G. W.; Hughes, G. J. Science 2010, 329, 305-309.

6. $\quad$ (a)Midelfort, K. S.; Kumar, R.; Han, S.; Karmilowicz, M. J.; McConnell, K.; Gehlhaar, D. K.; Mistry, A.; Chang, J. S.; Anderson, M.; Villalobos, A.; Minshull, J.; Govindarajan, S.; Wong, J. W. Protein Engineering Design \& Selection 2013, 26, 25-33. (b)Park, E. S.; Park, S. R.; Han, S. W.; Dong, J. Y.; Shin, J. S. Advanced Synthesis \& Catalysis 2014, 356, 212-220.(c) Han, S. W.; Park, E. S.; Dong, J. Y.; Shin, J. S. Advanced Synthesis \& Catalysis 2015, 357, 2712-2720; (d) Han, S. W.; Park, E. S.; Dong, J. Y.; Shin, J. S. Advanced Synthesis \& Catalysis 2015, 357, 1732-1740. (e)Nobili, A.; Steffen-Munsberg, F.; Kohls, H.; Trentin, I.; Schulzke, C.; Hohne, M.; Bornscheuer, U. T. Chemcatchem 2015, 7, 757-760. (f)Genz, M.; Vickers, C.; van den Bergh, T.; Joosten, H. J.; Dorr, M.; Hohne, M.; Bornscheuer, U. T. Int J Mol Sci 2015, 16, 26953-63. (g)Cho, B. K.; Park, H. Y.; Seo, J. H.; Kim, J.; Kang, T. J.; Lee, B. S.; Kim, B. G. Biotechnol Bioeng 2008, 99, 275-84. (h) Pavlidis, I. V.; Weiß, M. S.; Genz, M.; Spurr, P.; Hanlon, S. P.; Wirz, B.; Iding, H.; Bornscheuer, U. T. Nat. Chem. 2016, doi:10.1038/nchem.2578.

7. Gaussian 09, R. A., Frisch, M. J. ; Trucks, G. W.; Schlegel, H. B.; Scuseria, G. E.; Robb, M. A.; Cheeseman, J. R.; Scalmani, G.; Barone, V.; Mennucci, B.; Petersson, G. A.; Nakatsuji, H.; Caricato, M.; Li, X.; Hratchian, H. P.; Izmaylov, A. F.; Bloino, J.; Zheng, G.; Sonnenberg, J. L.; Hada, M.; Ehara, M.; Toyota, K.; Fukuda, R.; Hasegawa, J.; Ishida, M.; Nakajima, T.; 
Honda, Y.; Kitao, O.; Nakai, H.; Vreven, T.; Montgomery, J. A., Jr.; Peralta, J. E.; Ogliaro, F.; Bearpark, M.; Heyd, J. J.; Brothers, E.; Kudin, K. N.; Staroverov, V. N.; Kobayashi, R.; Normand, J.; Raghavachari, K.; Rendell, A.; Burant, J. C.; Iyengar, S. S.; Tomasi, J.; Cossi, M.; Rega, N.; Millam, J. M.; Klene, M.; Knox, J. E.; Cross, J. B.; Bakken, V.; Adamo, C.; Jaramillo, J.; Gomperts, R.; Stratmann, R. E.; Yazyev, O.; Austin, A. J.; Cammi, R.; Pomelli, C.; Ochterski, J. W.; Martin, R. L.; Morokuma, K.; Zakrzewski, V. G.; Voth, G. A.; Salvador, P.; Dannenberg, J. J.; Dapprich, S.; Daniels, A. D.; Farkas, Ö.; Foresman, J. B.; Ortiz, J. V.; Cioslowski, J.; Fox, D. J. Gaussian, Inc., Wallingford CT, 2009.; 2009.

8. (a) Lee, C. T.; Yang, W. T.; Parr, R. G. Physical review B, Condensed Matter 1988, 37, 785-789; (b) Becke, A. D. J Chem Phys 1993, 98, 5648-5652.

9. $\quad$ Carvalho, A. T. P.; Teixeira, A. F. S.; Ramos, M. J. Journal of Computational Chemistry 2013, 34, 1540-1548.

10. Miertus, S.; Scrocco, E.; Tomasi, J. Chem. Phys. 1981, 55, 117-129.

11. Bayly, C. I.; Cieplak, P.; Cornell, W. D.; Kollman, P. A. J. Phys. Chem. 1993, 97, 1026910280.

12. Guex, N.; Peitsch, M. C. Electrophoresis 1997, 18, 2714-23.

13. (a) Olson, A. J.; Morris, G. M.; Goodsell, D. S.; Halliday, R. S.; Huey, R.; Hart, W. E.; Belew, R. K. Journal of Computational Chemistry 1998, 19, 1639-1662; (b) Huey, R.; Morris, G. M.; Olson, A. J.; Goodsell, D. S. Journal of Computational Chemistry 2007, 28, 1145-1152. 14. D.A. Case, J. T. B., R.M. Betz, D.S. Cerutti, T.E. Cheatham, III, T.A. Darden, R.E. Duke, T.J. Giese, H. Gohlke, A.W. Goetz, N. Homeyer, S. Izadi, P. Janowski, J. Kaus, A. Kovalenko, T.S. Lee, S. LeGrand, P. Li, T. Luchko, R. Luo, B. Madej, K.M. Merz, G. Monard, P. Needham, H. Nguyen, H.T. Nguyen, I. Omelyan, A. Onufriev, D.R. Roe, A. Roitberg, R. Salomon-Ferrer, C.L. Simmerling, W. Smith, J. Swails, R.C. Walker, J. Wang, R.M. Wolf, X. Wu, D.M. York and P.A. Kollman Amber 2015, University of California, San Francisco., 2015.

15. Hornak, V.; Abel, R.; Okur, A.; Strockbine, B.; Roitberg, A.; Simmerling, C. ProteinsStructure Function and Bioinformatics 2006, 65, 712-725.

16. Wang, J. M.; Wolf, R. M.; Caldwell, J. W.; Kollman, P. A.; Case, D. A. Journal of Computational Chemistry 2005, 26, 114-114.

17. Ryckaert, J. P.; Ciccotti, G.; Berendsen, H. J. C. Journal of Computational Physics 1977, 23, 327-341.

18. Darden, T.; York, D.; Pedersen, L. Journal of Chemical Physics 1993, 98, 10089-10092.

19. Kuipers, R. K.; Joosten, H. J.; Verwiel, E.; Paans, S.; Akerboom, J.; van der Oost, J.; Leferink, N. G. H.; van Berkel, W. J. H.; Vriend, G.; Schaap, P. J. Proteins: Structure Function and Bioinformatics 2009, 76, 608-616.

20 Kuipers, R. K.; Joosten, H. J.; van Berkel, W. J.; Leferink, N. G.; Rooijen, E.; Ittmann, E.; van Zimmeren, F.; Jochens, H.; Bornscheuer, U.; Vriend, G.; dos Santos, V. A.; Schaap, P. J. Proteins: Structure Function and Bioinformatics 2010, 78, 2101-13.

21. Dourado, D. F. A. R.; Flores, S. C. Proteins-Structure Function and Bioinformatics 2014, 82, 2681-2690.

22. Flores, S.; Sherman, M.; Bruns, C.; Eastman, P.; Altman, R. IEEE Transactions in Computational Biology and Bioinformatics 2010, 8, 1247-1257.

23. Guerois, R.; Nielsen, J. E.; Serrano, L. J Mol Biol 2002, 320, 369-87.

24. $\quad$ Park, E. S.; Shin, J. S. Enzyme Microb Technol 2011, 49, 380-7.

25. Cassimjee, K. E.; Manta, B.; Himo, F. Org Biomol Chem 2015, 13, 8453-64. 
26. (a) Valley, C. C.; Cembran, A.; Perlmutter, J. D.; Lewis, A. K.; Labello, N. P.; Gao, J.; Sachs, J. N. Journal of Biological Chemistry 2012, 287, 34979-34991; (b) Ringer, A. L.;

Senenko, A.; Sherrill, C. D. Protein Science 2007, 16, 2216-2223.

27. Aledo, J. C.; Canton, F. R.; Veredas, F. J. Sci Rep-Uk 2015, 5, DOI: 10.1038/srep16955.

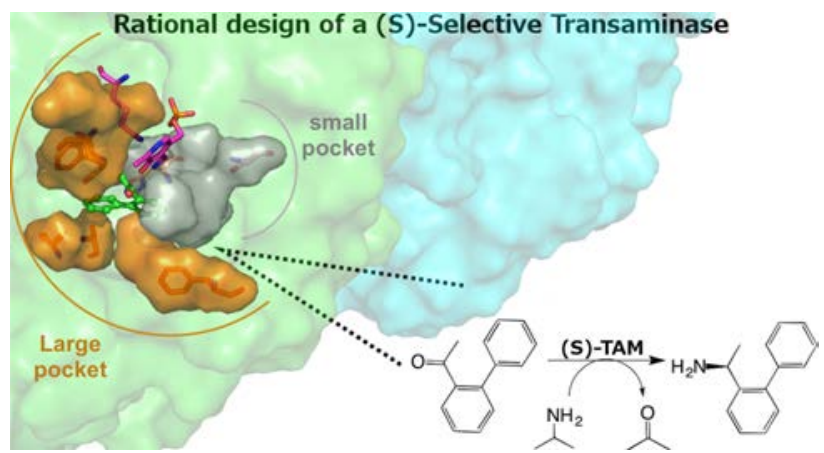

